\title{
Gobernabilidad neoliberal y movimientos indígenas en América Latina*
}

\author{
Rodrigo Navarrete Saavedra \\ Universidad Bolivariana, Los Ángeles, Chile. Correo electrónico: \\ navarretesaavedra.ibero@usal.es
}

\begin{abstract}
Resumen: El trabajo busca situar el análisis de los movimientos indígenas latinoamericanos dentro del desarrollo global del capitalismo y el sistema-mundo moderno, tratando de seguir una lectura decolonial de dichos procesos. Se postula que el neoliberalismo representa la encarnación actual de dicho sistema, pero que además simboliza un proyecto cultural que otorga criterios para el diseño de políticas de gobernabilidad en materia indígena. Se revisa la trayectoria actual de los movimientos indígenas en relación con las diferentes estrategias de gobernabilidad Estatal implementadas en tres regiones latinoamericanas: Mesoamérica, los países Andinos y el Cono Sur. Finalmente se analiza el potencial transformador y contrahegemónico de los movimientos indígenas contemporáneos, en cuanto intentan renovar valores y significados culturales, cuestionar el sistema de relaciones de poder y promover una comprensión alternativa del desarrollo. decolonial.

Palabras clave: gobernabilidad neoliberal, movimientos indígenas, giro
\end{abstract}

\section{Neoliberal governance and indigenous movements in Latin America}

\begin{abstract}
This paper aims to place the analysis of indigenous movements within the global development of capitalism and the modern world-system, trying to offer a decolonial reading of these processes. It has been said that neoliberalism represents the current incarnation of that system, but also symbolizes a cultural project that provides criteria for designing governance policies on indigenous issues. Besides, we review the current trajectory of indigenous movements related to the various state governance strategies, implemented in three Latin American regions: Mesoamerica, the Andean countries and the Southern Cone. Finally, we analyze the counter-hegemonic and transformative potential of contemporary indigenous movements, in attempting to renew cultural values and meanings, questioning the system of power relations and promoting an alternative understanding of develpmett
\end{abstract} shift.

Key words: neoliberal governance, indigenous movements, decolonial

\section{Governança neoliberal e Movimentos indígenas na América Latina}

Resumo: Este artigo procura situar a análise dos movimentos indígenas da Améri- 
ca Latina no desenvolvimento mundial do capitalismo e do sistema mundial moderno, tentando seguir-colonial leitura desses processos. Supõe-se que o neoliberalismo representa a encarnação atual do sistema, mas também simboliza um projeto cultural que fornece os critérios para a concepção de políticas de governança indígena. Nós revemos o caminho atual dos movimentos indígenas em relação às várias estratégias de governo do Estado, implementado em três regiões da América Latina: América Central, Comunidade Andina e do Cone Sul. Finalmente, analisamos o potencial transformador, ao contrário dos movimentos indígenas, na tentativa de renovar os valores e significados culturais, questionando o sistema de relações de poder e promover um entendimento alternativo de desenvolvimento. decolonial.

Palavras-chave: Governança neoliberal, movimentos indígenas, giro

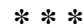

\section{Capitalismo, Sistema-Mundo moderno/colonial y subalternidad indígena}

El pensador norteamericano Immanuel Wallerstein (2003) postula que el capitalismo es el primer sistema-mundo de alcance genuinamente global, pues todos los sistemas históricos preexistentes estaban localizados geográficamente en un nivel menor, y que o colapsaban o terminaban por transformarse en imperios-mundo, es decir, mundos (aunque sin el alcance global del capitalismo) articulados en base a un proyecto de control político, y no en base a una economía-mundo, cuya especificidad radica en que son los límites de la economía los que configuran literalmente dicho mundo (concepto que Braudel utiliza en su obra sobre El Mediterráneo). Con la incorporación de América en los intercambios mercantiles, se inicia una nueva economía-mundo: el capitalismo (que articula unos procesos de producción, unas cadenas mercantiles y una división internacional del trabajo a nivel global). Es decir, Wallerstein adelanta hacia el siglo XVI el inicio del capitalismo como sistema histórico, mientras que gran parte del mundo académico convencional ubica su inicio un par de siglos más tarde con la revolución industrial inglesa. Este doble desplazamiento teórico, desde el mediterráneo hacia el atlántico como escenario del intercambio mercantil a una escala global, y hacia el siglo XVI, son fundamentales para debatir la concepción eurocéntrica del capitalismo y de la modernidad (Mignolo, 2003). Por ejemplo para el filósofo argentino Enrique Dussel (1998 \& 2000), quien aprovecha este giro geopolítico de Wallerstein para ofrecer una reinterpretación global de la modernidad, superando la visión europea que la entiende como producto del desarrollo de sus propias tradiciones internas: la filosofía griega, el imperio romano y la tradición judeocristiana (con sus matices esta versión que Dussel denomina “provinciana” de la modernidad va de Hegel a Habermas), y destacando el rol del "otro", de las colonias y de las tradiciones no occidentales como fundamento dialéctico del discurso moderno y de la razón moderna, aunque sea a través de su negación e inferiorización. 
Para Dussel (1998) la racionalidad moderna es producto del papel central que asume Europa en la gestión del sistema-mundo inaugurado en 1492, y en ningún caso producto del desarrollo de sus "tradiciones internas superiores”. De este modo, toma 1492 como momento fundacional de la modernidad, una primera modernidad, pues ya se comienza a construir el escenario de una sola Historia Mundial en la cual los imperios o sistemas culturales preexistentes dejan de coexistir entre sí y pasan a ser concebidos, por primera vez, como las periferias de un solo centro: Europa. Es el momento en el que surge el eurocentrismo de una cultura que no solo es etnocéntrica sino además universalista. Es esta autopercepción como referente universal lo específico de la civilización occidental, señala Sousa Santos (2005). La colonialidad es la otra cara de la modernidad, aclarando así su función ambigua: por un lado como emancipación y por otro como cultura de la violencia (Dussel, 2000).

Según Wallerstein (2003) durante los siglos XIV y XV Europa no era para nada la región más avanzada en términos tecnológicos, de conocimiento humano, ni de fuerzas productivas. Marco Polo, que provenía de una de las subregiones cultural y económicamente más “avanzadas” de Europa, se sintió totalmente abrumado por lo que encontró en sus viajes por Asia. El descubrimiento de América es por lo tanto fundamental para comprender la configuración del sistema-mundo, el establecimiento de Europa como centro del sistema mundial de explotación económica y dominación cultural y, en este escenario, el desarrollo del discurso científico y de las ciencias sociales en particular. Es el proceso mediante el cual Occidente deja de considerarse una cultura, solo una cultura más, como ejemplifica Latour (citado en Lander, 2000: ) “...nosotros los occidentales no podemos ser una cultura más entre otras, ya que nosotros también movilizamos a la naturaleza (...) ellos hagan lo que hagan, no importa si es adaptado, regulado o funcional, ellos siempre permanecen ciegos al interior de esta confusión. Nosotros hagamos lo que hagamos, no importa cuan criminal o imperialista podamos ser, escapamos a la prisión de lo social y del lenguaje para lograr acceso a las cosas mismas a través de un portón de salida providencial, el del conocimiento científico”.

La necesidad de organización social y control de la vida humana en el emergente modo de producción capitalista hizo necesaria la conformación de una instancia central desde la cual coordinar los mecanismos de control. Esta fue el Estado y los sistemas de Estados, garantes de la organización racional de la vida humana bajo criterios científicos. Por lo tanto, las ciencias sociales no son un elemento aditivo a los marcos de organización del Estado-nación y el establecimiento de una estructura social racialmente definida, sino que son elementos constitutivos de dichos procesos (Castro-Gómez, 2000). El desarrollo de las ciencias sociales a fines del siglo XIX, la economía, la ciencia política, la sociología, la antropología y la historia, principalmente, son necesarias para generar una plataforma de observación científica sobre el mundo social que se quería gobernar, y en este sentido se puede conectar con la invención de Occidente, es decir, como en este relato de Europa sobre si misma, la modernidad y el discurso 
científico como su correlato sería la culminación del progreso cultural, una nueva etapa alcanzada por Occidente producto de la evolución interna de sus tradiciones culturales; un nuevo estadio de desarrollo de la sociedad en los términos de Comte. No obstante, es evidente que este relato universal no podría ser inteligible sin la existencia de un Otro de quien distinguirse y diferenciarse, con lo cual el "nuevo mundo", los proyectos civilizatorios prehispánicos son la otra cara de la modernidad, son el "pasado", lo "inferior", lo "tradicional”. Los indígenas al carecer de Estado y de Constitución, pasan a ser evidentemente representantes de una forma de vida inferior, prehistórica, carente de todo derecho frente al colonizador (Lander, 2000).

Esta visión nos permite entender la modernidad y la conformación del sistema capitalista mundial como un proceso integral, global, que posiciona a Europa como su centro y al resto de las regiones como periferias y semiperiferias. No hay una civilización y unos valores que nacen en Europa y que se extienden gracias a su superioridad intrínseca hacia el resto del mundo como pretenden hacer creer el discurso eurocéntrico, sino que sería un proceso dialéctico, las periferias son la otra cara de la moneda, de la misma moneda; Europa y occidente se construye mientras conquista, coloniza y subordina nuevas regiones. El liberalismo y la democracia son solo una cara de la moneda preservada para el centro, la esclavitud, la encomienda, la hacienda, el peonaje, son las formas que promueve la dinámica desigual del mismo sistema mundial en las áreas periféricas.

\section{Globalización y emergencia indígena}

De acuerdo a lo anterior podemos afirmar que el "fenómeno étnico" ha sido una dimensión fundamental para el desarrollo del capitalismo y el sistema-mundo moderno/colonial, pues todos los localismos, los particularismos culturales y étnicos pasaron a representar un obstáculo para la expansión del capital a escala global y sus ideologías universalizadoras (Balibar \& Wallerstein, 1991), y por lo tanto la historia moderna es también la historia del proyecto de dominación de la civilización europea sobre todo el resto de la diversidad cultural y étnica mundial.

En este marco podemos entender la organización colonial/racial del mundo, que fue instaurada por Europa y sus ideologías, al asumir ésta la gestión hegemónica del sistema-mundo a partir del siglo XVI y XVII (Dussel, 1998). La construcción del concepto de raza, que permite la organización del mundo colonial en expansión es un elemento clave, un bastión de la matriz de poder que permite la articulación del capitalismo a escala global. La colonialidad, como elemento constitutivo y específico del patrón mundial de poder capitalista, se funda en la imposición de esta clasificación racial/étnica de la población como piedra angular de dicho patrón de poder y opera en cada uno de los planos, ámbitos y dimensiones, materiales y subjetivas, de la existencia cotidiana y la vida societal (Quijano, 2000b). De este modo, la clasificación del poder colonial en términos étnico/raciales (blancos europeos, indios, amarillos, negros, mestizos, mula- 
tos, etc.), permitió una jerarquización de la fuerza de trabajo donde el racismo institucional operó como justificación ideológica de la distribución sumamente desigual de los roles y recompensas dentro del sistema global (Wallerstein, 2003 \& 2005; Quijano, 2000a).

Es decir, el “fenómeno étnico” ha estado ligado de forma intrínseca al desarrollo del capitalismo, y por lo tanto resultaría arbitrario intentar localizarlo como un fenómeno totalmente nuevo, emergente de la actual era de la información y el capitalismo financiero global, más bien el actual resurgimiento de la etnicidad a nivel global sería un síntoma de la crisis de dicho sistema de 500 años de existencia (Quijano, 2005). No se puede olvidar que el racismo es una construcción ideológica del discurso científico del siglo XVIII, y que los movimientos de liberación nacional y las luchas por la descolonización fueron, junto con los movimientos obreros, las principales luchas antisistémicas durante el siglo XIX y el XX (Arrighi, Hopkins \& Wallerstein, 1999).

Si pensamos en la "gestión de la etnicidad" en América Latina, es evidente que ha sido un asunto de primera importancia desde la creación misma del Estado y la invención de la nación, en el siglo XIX. La incorporación simbólica de los indígenas en la “comunidad imaginada” (Anderson, 1993) de los criollos independistas (Estado oligárquico) operará en la práctica como una exclusión y subordinación real a través de la usurpación de tierras y la consolidación de instituciones de servidumbre como la hacienda o el denominado gamonalismo en el Perú (Degregori, 1993). Posteriormente durante el Estado desarrollista, desde los años 30 del siglo XX, se realizará la incorporación masiva de nuevos actores sociales a la ciudadanía de Estado (Assies, Calderón \& Salman, 2002), donde los indígenas son incorporados de forma subordinada como campesinos o como proletariado urbano marginal, debido a la migración campo-ciudad. Es decir, son incorporados (al menos retóricamente) en cuanto a su posición en una estructura ocupacional y en términos de clase, tal como interpelaba el Estado desarrollista y su corporativismo, pero no en cuanto a su identidad étnico cultural.

En este marco, lo que cabría señalar entonces, es que lo que se denomina hoy globalización viene a representar una radicalización de una lógica profunda del sistema-mundo moderno, una nueva etapa del capitalismo tecnológicamente avanzado basado en las impresionantes transformaciones en las tecnologías de la comunicación y la información, y en el despliegue mundial del capital financiero que puede moverse a una velocidad sin precedentes, lo que altera la comprensión del espacio-tiempo tradicional moderno y socava la capacidad del Estado-Nación para regular la política y lo social hacia adentro (Larraín, 2001; Castro-Gómez, 2000). Este proceso implica una serie de transformaciones socioculturales, pues modifica las dinámicas de identificación y nos pone en contacto de una nueva manera con una serie de “otros” en relación a los cuales redefinir la identidad y la diferencia. El resurgimiento de la cuestión étnica en este escenario de economía globalizada, de crisis del Estado desarrollista en 
América Latina y del Estado de Bienestar en Europa, y de transformaciones socioculturales globales, representa entonces algunas continuidades históricas pero también una serie de características totalmente nuevas.

Para el caso de América Latina lo más interesante de este proceso es la renovada visibilidad del movimiento indígena y un protagonismo político sin precedentes. Como señala Quijano (2005) la crisis del desarrollismo, con la desintegración de la estructura productiva y, consecuentemente, de las identidades campesinas y de clase que este promovía, significó una reetnificación de la identidad y una revalorización de identidades étnicas que nunca se disolvieron completamente. La globalización, con su nuevo universo de comunicación y virtualidad, ha permitido a las antes aisladas comunidades indígenas rurales, en medio de esta crisis de las identidades de clase, conectarse con sus pares indígenas en el resto del continente y reconocerse dentro de una historia común de subordinación y dominación a la lógica colonial y al capital. La correspondiente crisis de la izquierda ha favorecido aún más la construcción de esta memoria y de esta identidad como precursores de acción política. Tampoco puede desconocerse la influencia de la doble transición en la región: tanto de regímenes autoritarios hacia emergentes democracias, como de una limitada economía desarrollista hacia un modelo neoliberal. La primera representa la apertura de una estructura de oportunidades políticas (EOP), en cuanto favorece la movilización y la acción colectiva, mientras la segunda transición representa la pérdida de los pocos derechos sociales que pudieron tener los sectores más marginales de la sociedad, la exposición a nuevos riesgos, la apertura de sus territorios a los proyectos del capital trasnacional y la ausencia del Estado como garante de mínimos derechos, lo que ha desencadenado el surgimiento de nuevas formas de protesta y acción política.

\section{Los nuevos movimientos sociales de raíz indígena en América Latina}

Si bien gran parte de las teorías políticas y sociales para comprender la actual emergencia indígena en América Latina evitan referirse a la historia, pues parten de postulados de la elección racional, las estructuras de oportunidades o postulan la absoluta contingencia de este fenómeno como respuesta instrumental a la crisis del Estado-nación, crisis de las identidades de clase y los procesos de globalización, no me parece totalmente creíble renunciar a inscribir estos procesos dentro de dinámicas históricas más amplias. Es decir, sin compartir para nada una visión esencialista o primordialista de la identidad y la cultura, para la cual se trataría de identidades indígenas que permanecen cristalizadas por siglos y que han sobrevivido a la colonización y la construcción del Estado por lo que cada levantamiento a lo largo de esta historia sería más o menos lo mismo (un alzamiento de la tradición contra la modernidad), tampoco me parece totalmente creíble una versión totalizadora de la modernidad y la globalización que niega cualquier posibilidad de diferencia, para la cual la etnicidad sería un mero instrumento de empresarios políticos en tiempos de crisis de otras 
identidades políticas más efectivas (Máiz, 2005). Según este planteamiento los movimientos indígenas sólo serían la forma más económica y conveniente (como sostiene la rational choice) para canalizar demandas políticas modernas hacia el Estado. Me parece que si la memoria es un elemento fundamental para la socialización y para actuar identitariamente en términos políticos, no puede desconocerse entonces la importancia de las representaciones simbólicas, lo subalterno que resiste a la imposición hegemónica y la identificación social como continuidad en una historia de colonialismo, negación, subordinación y explotación. Es decir, si bien no hay duda de que la actual politización de la identidad étnica es una producción contingente (como cualquier otra) y que la etnicidad es sólo una de las múltiples identidades sociales posibles de politización, también resulta necesario considerar que dichas identidades apelan a una memoria histórica y a una diferencial colonial establecida por la dinámica misma del poder desde el contacto entre conquistadores e indígenas y que, bajo diversas formas, atraviesa transversalmente la historia del proyecto de Estado-nación en el continente, lo cual le otorga una especificidad irreductible a otras identidades sociales, de clase o políticas, que es su potencialidad descolonizadora.

Como señala Escobar (2005) es crucial cuestionar la idea ampliamente aceptada de que la modernidad es ahora una fuerza universal e inescapable, que la globalización implica la radicalización de la modernidad, y de que en adelante "la modernidad está en todas partes". Siguiendo a Dussel (1998) señala que es necesario visibilizar el lado oculto de la modernidad, es decir su colonialidad, a través de los conocimientos subalternos y las prácticas culturales que ésta ha suprimido, invisivilizado y descalificado. Desde esta perspectiva, no cabe afirmar en tono universal que todos los movimientos indígenas son expresiones políticas instrumentales que son creadas autointeresadamente por empresarios políticos para aprovechar un vacío de representación. Pero tampoco son una repetición del pasado. Posiblemente entenderlos como movimientos desde la diferencia colonial (Flórez-Flórez, 2005) permita evitar caer en estos extremos primordialistas o absolutamente contingentes y autointeresados, y permita captar su particular diferencia como politización de lo que estaba al margen, negado e invisivilizado por la política moderna y los sujetos privilegiados de ésta.

\section{La particular subordinación indígena en la construcción del Estado-nación: Mesoamérica, Región Andina y Cono Sur}

A grandes rasgos podríamos identificar ciertas características particulares de la construcción de Estado y nación en estas regiones, lo que permitiría localizar la posición simbólica que les fue impuesta a los pueblos indígenas preexistentes al Estado y la nación criolla, y por lo tanto las diferentes prácticas que se han podido operar sobre éstos en diversos mo- 
mentos de la historia nacional. Es decir, las distintas "narrativas" sobre lo indígena que subyacen la construcción de Estado y nación.

En Mesoamérica quizás el caso más conocido es el de la construcción del Estado en México, donde se podría afirmar que existió una apropiación selectiva del pasado. Es decir, las grandes civilizaciones indígenas mesoamericanas son reconocidas por el discurso oficial, se rescata su gran pasado prehispánico y se incorporan una serie de símbolos indígenas a la nación mexicana. La revolución mexicana de inicios del siglo XX implicará un avance real más o menos profundo en la descolonización del poder antes de ser contenida y derrotada (Quijano, 2000b). Así finalmente se profundizará esta política de apropiación selectiva del pasado, donde se tratará de "mexicanizar al indio", para incorporarlo definitivamente al nuevo proyecto de nación. Parafraseando a la investigadora Natividad Gutiérrez Chong, es una narrativa del tipo "si hay un pasado indígena, pero ¿qué nos conviene rescatar?”. Esta construcción social permite comprender la creación y desarrollo del indigenismo de Estado en México durante una importante parte del siglo XX, con el fin de construir una identidad nacional mexicana, una cultura cívica y una modernización de los indígenas mediante formas “"respetuosas”” de su identidad.

En el caso de los Países Andinos (sobretodo Perú, Bolivia y Ecuador) la población indígena es fuertemente significativa, cerca del 90\% de la población está compuesta por “indígena, mestizos y negros” al comienzo de los procesos de Independencia. La pequeña minoría blanca asumió todo el poder, excluyendo a las amplias mayorías de la creación y control del Estado. El Estado pasó entonces a ser, de facto, un sistema privado de control colectivo (Quijano, 2005). Se trata de la paradoja, más visible que en el caso anterior, de Estados independientes articulados a sociedades coloniales, donde se mantendrán y extenderán procesos de usurpación territorial a los indígenas e instituciones serviles como la hacienda o el denominado gamonalismo en el caso de Perú (Degregori, 1991). La narrativa en este caso es del tipo "el pasado no tiene nada que ver con nosotros... o hubo un pasado pero no nos interesa”. Los dueños del poder político y del Estado, la minoría blanca, no solo no tienen intereses en común con la población indígena y negra, sino que sus intereses son exactamente antagónicos, pues éstos son efectivamente sus siervos y sus esclavos (Quijano, 2000a). Son casos de Estados que no son de ninguna manera "nacionales", a menos que se entienda que la elite señorial blanca terrateniente es representante legítimo de sus siervos y esclavos.

El caso del Cono Sur (Argentina, Uruguay, Chile) el proceso es distinto, pues se produjo un brutal exterminio de la población indígena, que no tenía disponibilidad para transformarse en fuerza de trabajo colonial (Quijano, 2000a), por lo que se logró un grado de homogeneidad étnica mayor (en el sentido de menor participación indígena y negra). En estos países también la presencia de esclavos negros fue mucho menos significativa que el resto de las regiones dominadas por españoles y portugueses. La elite Estatal considera necesaria la conquista de los territorios indígenas 
que habían sobrevivido aislándose, por lo que se realizan operaciones militares de anexión, la denominada "Pacificación de la Araucanía en Chile” y la "Conquista del Desierto" en Argentina a fines del siglo XIX. La narrativa general que se podría utilizar en estos casos sería "no hubo, ni nunca habrá indígenas", es la narrativa de la negación del pasado que es brutalmente efectiva. Son Estados profundamente eurocéntricos y cuyo proyecto de identidad nacional es marcadamente anti-indígena.

No obstante, me gustaría realizar una pequeña aclaración para el caso de Chile. Su proceso histórico le presenta más traumas identitarios que el argentino o uruguayo. En el caso Argentino, debido a enormes flujos migratorios europeos el proyecto identitario nacional es muy débil, hasta avanzado el siglo XX se siguen considerando europeos exiliados en la pampa, por lo que una importante mayoría no tiene problemas de conciencia con el exterminio indígena, ni les preocupa no tenerlo. El caso chileno es más complejo, los indígenas hasta el valle central son subordinados e incorporados como el segmento más bajo de la estructura social de la colonia, promoviendo el mestizaje y la aculturación, mientras hacia el sur los mapuche cuentan con autonomía de sus territorios pues resistieron a los españoles y ganaron una frontera de guerra por parte de la Corona. La construcción nacional del Estado y la nación, entonces recurre a esta imagen del guerrero mapuche para incorporarla en el mito de la nación chilena. El mapuche es incorporado a la nación simbólicamente (no los aymaras, diaguitas, collas, atacameños, quechuas, yaganes, rapa nui, ni kawashkar), el mapuche mítico, mientras el real aún mantenía su autonomía al sur del río Bío-Bío. Entonces el mapuche mítico de la construcción de la nación debe ser, a fines del siglo XIX y comienzos del XX, enfrentado militarmente para incorporar sus territorios a la dinámica agroexportadora (boom del trigo). La conciencia nacional chilena no es indiferente frente a la situación de los indígenas. Un enorme sector popular, las clases más bajas, se reconocen en un origen mestizo y de alguna forma subsiste la intuición de la injusticia cometida frente a las comunidades mapuche que resistieron por siglos al conquistador español, pero que fueron finalmente derrotados por el propio Estado chileno, reducidas en minifundios, discriminadas y empobrecidas. La idea de trauma, de conflicto con la propia historia, de incomodidad con el origen de la nación, está sin duda presente en la intersubjetividad de gran parte de los chilenos (Bengoa, 1999). En Chile, a diferencia de Argentina, los militares que derrotaron a los mapuche no son héroes populares, no se conmemora su invasión a la frontera indígena (excepto en grupos muy puntuales), la incomodidad con el pasado es mucho más fuerte.

\section{Movimientos indígenas y gobernabilidad neoliberal en el contexto actual}

No es mi intención revisar las explicaciones que se suelen dar para comprender la emergencia de una politización indígena en términos específicamente étnicos desde la década de los 70s y 80s, pues existe mu- 
cho material al respecto. La crisis del estado desarrollista y, consecuentemente, de las identidades de clase y campesinas a las que éste y toda la sociedad del momento interpelaba, la descompresión del mundo rural latinoamericano de la presión de la lógica del comunismo internacional durante la guerra fría, la desaparición de las políticas agrarias corporativistas y la nueva irrupción del capital neoliberal minero, agrario y forestal en los campos, la apertura de una nueva estructura de oportunidades políticas por las transiciones hacia regimenes democráticos, la globalización y su impacto en la crisis de la cultura y el espacio-tiempo hegemonizado por el Estado que permite un nuevo énfasis tanto en lo local como en lo global, el agotamiento del proyecto moderno eurocéntrico, etc. suelen ser algunos de los factores esgrimidos para explicar este fenómeno (por ejemplo, Bengoa, 2000; Máiz, 2005, Martí, 2007, entre otros).

Lo que se pretende es apenas presentar algunos elementos de dicha movilización y de la respuesta de gobernabilidad generada desde los diferentes Estados en un escenario neoliberal. Por tratarse solo de algunos mínimos comentarios aproximativos, es posible que las situaciones sean extremadamente simplificadas, pero se entiende que se trata solo de un ejercicio aproximativo, más centrado en las conexiones de sentido posibles que en la exactitud histórica.

En el caso Mesoamericano, el levantamiento armado de los zapatistas en Chiapas en 1994, representa sin dudas el más visible y simbólico de la región. Pese a tratarse de una insurrección armada, lo que para algunos observadores demuestra su anclaje en la política tradicional de la izquierda maoísta, en realidad el EZLN representa un amplísimo repertorio de movilización, que incluye un renovado discurso de pluralismo y deliberación ("un mundo donde quepan muchos mundos"), construcción de estructuras organizativas relativamente horizontales ("mandar obedeciendo"), una revaloración de lo local frente a las lógicas de gobierno vertical y a distancia, un reconocimiento de la pluralidad étnica negada, etc. (Máiz, 2005). Además de tensiones, tires y aflojes, entre una estrategia localista e indigenista, y una estrategia universalista de construcción de una nueva izquierda global.

La estrategia de gobernabilidad estatal en materia indígena, si bien realizó un primer intento de aplastar militarmente el levantamiento, se ha caracterizado por una contradictoria política de avances y retrocesos. Es decir, si bien nunca ha desaparecido del todo la tensión militar pues el territorio está fuertemente rodeado por bases militares instaladas, por otra parte ha existido una variable respuesta en términos de reconocimientos jurídicos de derechos indígenas, una respuesta que incorpora tanto algunos elementos de real reconocimiento de la demanda zapatista con otras formas de neoindigenismo de Estado. No obstante, después de la aprobación unilateral en 2001 por parte del Congreso federal de reformas constitucionales en materia de derechos indígenas y el fallo de la Suprema Corte de Justicia ese mismo año, en contra de 331 controversias promovidas por autoridades de municipios mayoritariamente indígenas, se cerraron las posibilidades de 
reconocimiento legal a la autonomía y a la autodeterminación de los pueblos (Mora, 2007). La respuesta del EZLN que aglutina a gran parte de las comunidades en "resistencia”, fue optar por la autonomía por la vía de los hechos, desconociendo absolutamente al gobierno.

En este caso, el Estado ha mostrado su capacidad de incorporar parte de la demanda zapatista, de forma más bien simbólica, y de fomentar acuerdos para regular el conflicto, no obstante, también ha mostrado los límites de dicho reconocimiento al rechazar gran parte de la propuesta zapatista de reformas constitucionales en lo que parece ser una estrategia de desgaste para el EZLN que ya lleva 15 años de movilización. Parece que la estrategia de apropiación selectiva de elementos indígenas sigue profundamente arraigada en el Estado mexicano, por lo que muchas demandas del zapatismo han sido traducidas en términos neoindigenistas por la clase política. La Otra Campaña, declarada en 2005 por EZLN, intenta una nueva etapa de lucha que aglutine a amplios sectores de "izquierda anticapitalista” para un nuevo proyecto constituyente (Mora, 2007), asumiendo que dentro de un modelo de gobernabilidad neoliberal resulta imposible seguir avanzando tanto para las demandas indígenas como para un nuevo tipo de política local promovida por los zapatistas.

En la Región Andina, el desarrollo del movimiento indígena ha sido diferente, sobre todo en Ecuador y Bolivia, sociedades donde se han articulado numerosos movimientos sociales que exigen cambios profundos en la esfera política, económica y social de dichos Estados. La politización de la identidad étnica ha sido fundamental en estos procesos, donde los indígenas han mostrado un enorme poder de movilización social y de protesta. Son también los principales casos donde desde una densa red de movimientos sociales de base, se ha articulado una vía política electoral de corte étnico con resultados importantes, lo que Van Cott (2005) describe como el paso de movimientos a partidos étnicos, con un universo de nuevos desafíos y problemáticas.

En estos países se trata de una profunda transformación del Estado desde procesos constituyentes, pues los indígenas reclaman que es necesario refundar el Estado para que éste represente realmente a su población y permitir así una ciudadanía efectiva para los indígenas, la cual sería una ciudadanía diferenciada del resto (Pallares, 2007). Pachakutik, brazo político de CONAIE en Ecuador, ha mostrado las fricciones y contradicciones que conlleva pasar de un movimiento social indígena hacia un partido político que compite electoralmente en el sistema político que tanto se cuestiona, al mismo tiempo que se ha ido desarticulando la integralidad de dichas demandas, separando lo "étnico" de lo "no-étnico" en su interacción con el Estado y el sistema político (Barrera, 2004). En Bolivia, el enorme triunfo de Evo Morales Ayma, dirigente cocalero aymara apoyado por el Movimiento al Socialismo, que incorpora sectores indígenas pero también cocaleros, mineros y sectores medios disconformes con la política tradicional, ha mostrado la nueva politización del mundo indígena, inspirado en modificar radicalmente la sociedad y el Estado, y sobre todo replantea la 
situación de formas de organización social comunitarias como espacio de poder no estatal (Zibechi, 2007) que pretenden apoyar transformaciones políticas pero también cuidar su autonomía.

En estos casos resulta mucho más complejo identificar con claridad la gobernabilidad neoliberal vigente, puesto que los movimientos indígenas han sido parte fundamental del descontento social que ha logrado posicionar gobiernos con un mandato antineoliberal, no obstante, más allá de la desestructuración del sistema de partidos y que sectores privilegiados hayan perdido el poder político, estos sectores no han perdido de ninguna forma el poder económico. Se trataría de periodos de transición, donde se encuentran en disputa diferentes modelos de sociedad, lo que también ha aumentado la polarización de dichas sociedades, y conviven en tensión fuerzas radicalizadoras con medidas moderadas (Stefanoni, 2007). En ambos casos se trata de la emergencia política de un actor subalterno, marginalizado y excluido del poder político, que sin embargo ha mostrado el enorme peso de la etnicidad como factor de politización social, para exigir transformaciones de fondo en el Estado. Autonomías indígenas, plurinacionalismo, reforma agraria y control sobre los recursos, son algunos elementos de la agenda indígena que ha ayudado a llegar al poder tanto a Morales en Bolivia, como a Correa en Ecuador. Pero también dejan de manifiesto la resistencia de los grupos históricamente privilegiados a dichos cambios; en Bolivia sobretodo con la gran oposición que han organizado los departamentos orientales hacia la gestión de Morales y la "indigenización" del país, plasmado en los referendos autonomistas de las provincias más acomodadas y que se contraponen a las autonomías en clave indígena que promueve Morales; y en Ecuador se visualiza la debilitación del peso político de Pachakutik, frente a un proyecto más amplio de izquierdas y de descontento pero mucho más personalizado en Correa, mostrando que si bien el debate sobre la interculturalidad del país y del Estado llegó para quedarse, la etnicidad no es el único eje de articulación política (del sistema político) y que éste puede variar dependiendo de las condiciones y los aspectos del debate.

En términos de la gobernabilidad neoliberal en materia indígena, se trata de dos proyectos que en gran medida desafían dicha dinámica de poder, en cuanto buscan la transformación del modelo socioeconómico y el proyecto cultural que éste representa, no obstante, esta fuerza convive con tendencias más conciliadoras y se enfrenta a la resistencia de otros proyectos de sociedad que no han perdido para nada sus esperanzas de recuperar el control político luego de esta "aventura” populista, izquierdista e indigenista. También son ejemplos que vuelven a mostrar que la obtención del poder político no garantiza un avance progresivo en las demandas indígenas, sino que se trata de procesos mucho más complejos, pues implican un cuestionamiento de fondo a las relaciones de trabajo, de control de recursos y de socialización del poder.

Por último, en el caso del Cono Sur el proceso de politización indígena dista bastante de los casos anteriores. En dicha región los movimien- 
tos indígenas han sido fuertemente descalificados, criminalizados, reprimidos y se ha bloqueado toda posibilidad de fortalecimiento político de éstos. El pueblo mapuche al sur de Chile y Argentina, ha sido el que más potentemente ha dado señales de movilización social y ha planteado sus demandas tanto al Estado como al resto de los actores de influencia en los territorios en disputa (empresas, organizaciones locales, sociedad civil, etc.). Hoy la movilización mapuche en el sur de Argentina es ampliamente ignorada por los medios y por el resto de la sociedad, de hecho para muchos el conflicto mapuche sería un "problema" de Chile. El peso de la invisibilidad de los pueblos indígenas ha sido mayor en el Cono Sur, donde se trata de proyectos nacionales que se consideran más homogéneos (en termino de "blancura”) y eurocéntricos.

No obstante, en el caso chileno este velo ha sido desmontado varias veces en el siglo XX, sobre todo durante los años 60 y el gobierno de la UP. En dicho periodo de reformas agrarias, el pueblo mapuche fue un actor relevante, que agudizó la situación en el sur del país con las corridas de cercos y las tomas de fundos. En dictadura cuando se subdivide la comunidad indígena, se produce una importante movilización de los mapuche, a través de los centros culturales que eran la única forma de organización permitida por los militares. Y con la transición se inicia una nueva etapa de conflicto con el Estado y con los grandes intereses del capital en territorios del sur del país, donde el Estado ha articulado una estrategia de gobernabilidad de forma unilateral, que consiste en: definir la problemática indígena como un problema de campesinos pobres; y criminalizar la movilización social mapuche (Toledo Llancaqueo, 2007). Así se trata de una estrategia que combina la canalización selectiva de demandas, asistencialismo y represión, sin llegar hasta el momento a un reconocimiento de derechos indígenas colectivos y territoriales.

\section{Más allá de las estrategias de gobernabilidad neoliberal: el potencial contra-hegemómico de los movimientos indígenas del Sur}

En los tres casos, a pesar de sus diferencias, es posible observar algunas tendencias de la gobernabilidad neoliberal en materia indígena señaladas por Hale (2004). La separación entre derechos culturales (lengua, educación bilingüe, tradicionales, etc.) y empoderamiento político y económico parece una constante en todos los casos. La primera respuesta estatal ha sido "promover la cultura”, pero desvinculándola del tema del poder político y el control de los recursos que permiten efectivamente la subsistencia de una cultura. Quizás en Ecuador sea el caso más evidente, donde el propio movimiento indígena se va fortaleciendo en este proceso que para el Estado se trataba apenas de avanzar en estrategias de alfabetización rural con pertinencia cultural (Pallares, 2007). En este caso el movimiento constantemente presiona por ampliar la concepción de cultura que maneja el Estado para incorporar aspectos materiales que tienen que ver 
con el territorio y con el poder político. El caso chileno también es evidente, pues se inauguran toda una serie de programas de nuevo trato y verdad histórica, de educación intercultural bilingüe, al mismo tiempo que se criminaliza la movilización mapuche y se desaloja violentamente a quienes reclaman tierras y se judicializa a las comunidades que reivindican derechos.

Hale también señala que un principio cultural del neoliberalismo es el régimen productivo y la economía globalizada, es decir, es capaz de gestionar las demandas indígenas por seguridad en la tenencia y por acceso a tierras, pero siempre y cuando éstas entren de alguna forma al juego de la economía global o no representen un conflicto con intereses económicos de otros sectores más dinámicos e integrados. En este caso encontramos las limitaciones que se imponen a proyectos como las autonomías en Chiapas, en cuanto estas implican un proyecto económico distinto, que busca la desmercantilización de la tierra. También es el problema en el sur de Chile, donde el Estado y las empresas forestales han diseñado una serie de mecanismos para presionar a las comunidades para que éstas introduzcan plantaciones forestales en sus tierras, incluso a través de subsidios totales, con lo cual en el fondo el comunero legalmente sigue siendo dueño de su tierra, pero pierde toda capacidad de decisión y control sobre lo que produce y el destino de su producción.

La dicotomía entre el "indio bueno" y el "indio malo" elaborada por Hale y Millamán, sostiene que ésta distinción es un principio de la estrategia neoliberal de gobernabilidad, en cuanto permite separar a los indígenas entre quienes son obedientes y se adaptan a las nuevas dinámicas, de los indígenas que no aceptan dichas imposiciones y que promueven proyectos diferentes que chocan con la gestión de la economía y del poder de Estado. Esta estrategia es evidente en el caso chileno, donde se ha construido toda una imagen de "mapuche terrorista", al mismo tiempo que se instalan proyectos asistencialistas que buscan cooptar a las comunidades.

Me parece que es evidente que no hay una dirección clara ni nada que asegure un igual desarrollo del conflicto indígena en estas regiones. Depende de la naturaleza del propio movimiento, su nivel de politización y de las características del Estado y la nación que se confronta. En este sentido, mientras en México los zapatistas llevan ya 15 años de movilización, con autonomías de hecho y avances y retrocesos, en los países Andinos ha existido una enorme capacidad de politización étnica para promover la refundación del Estado plurinacional (Santos, 2007), en el Cono Sur y Chile en particular, el movimiento ha sido reprimido, incomprendido y judicializado. Me parece que tanto la historia de construcción de estado y nación es diferente en este caso, así como también la consolidación del modelo neoliberal, pues en Chile éste se instaura más de una década antes que el resto y en un escenario de autoritarismo político, lo que hace que existan hoy sectores demasiado privilegiados con dicho modelo y que éste jamás haya sido puesto en tela de juicio en la transición. Por lo anterior es que mientras el caso de Chiapas y de los Países Andinos han logrado desa- 
fiar la gobernabilidad neoliberal en materia indígena, con contradicciones, avances y retrocesos, en Chile se haya desarrollado una respuesta tan agresiva de parte del Estado, pues no se debe olvidar que Chile representa un ejemplo de inserción en la economía globalizada y de defensa del modelo neoliberal como "exitoso".

Un último aspecto a comentar tiene que ver con la potencialidad transformadora de los movimientos indígenas en la región, potencial que ha sido subestimado por gran parte de los estudioso de los movimientos sociales del norte. No obstante, el trabajo desarrollado por Escobar (2005) y por Flórez-Flórez (2005) ha mostrado con mucha agudeza como en tales interpretaciones persisten sesgos de una lectura eurocéntrica de la modernidad y la acción política. La argumentación es que si en Europa es posible que existan hoy "nuevos movimientos sociales" que representan una crítica de la modernidad y que ofrecen nuevos imaginarios socioculturales, organizativos y nuevos proyectos de convivencia social que permitirían cuestionar los límites de la racionalidad decimonónica, esto es imposible en América Latina puesto que no hemos llegado a esa etapa postmaterial propia de las sociedades de la abundancia. Como señala Escobar (2005), esta visión dicotómica (tradicional/moderno) que condena la acción colectiva latinoamericana a una mera demanda de servicios básicos al Estado, está presente a través de diversas formas, bastante explícitas, en el pensamiento de Laclau y Mouffe, de Touraine y de Melucci. Antes de llamarlos movimientos sociales los denominan: "movimientos populares" (Foweraker; Laclau y Mouffe), "movimientos sociohistóricos” (Touraine), "movimientos culturales" (Touraine y Khosrokhavar,) o simplemente, "viejas luchas" (Mainwarning y Viola). En la base de sus argumentos se halla la tesis común de que el atraso o el subdesarrollo, ha sido uno de los impedimentos fuertes para que la acción colectiva del Sur se consolide en movimientos sociales (Flórez-Flórez, 2005 y 2007).

Como señala Escobar (2005) y Flórez-Flórez (2005 y 2007) según esta mirada nada nuevo puede venir del Sur, todo lo nuevo siempre debe moverse desde Europa hacia el resto del mundo. Esta lectura limita el impacto de los movimientos sociales latinoamericanos y, con mayor razón los movimientos de raíz indígena, considerados actores “tradicionales” y siempre orientados hacia el pasado, dejándolos en una situación de subordinación a los movimientos europeos, que son considerados los únicos que pueden entregar luces sobre nuevas culturas políticas, nuevas formas de subjetividad política y de articulación social. Pero como señala Flórez-Flórez (2005:10) "los movimientos del Sur no se han limitado a alcanzar la modernidad. Por el contrario, uno de sus éxitos ha sido cuestionarla profundamente poniendo sobre la mesa la crisis del desarrollismo; es decir: el impostergable reconocimiento del fracaso de un modelo de cambio ilimitado, universal y acumulativo y el consecuente reclamo, ya no de un "desarrollo alternativo" sino de "alternativas al desarrollo". En ese sentido, los movimientos nos han llamado la atención sobre la urgencia de pensar la transformación social yendo más allá de la quimera del progreso. A la par que evidencian esta crisis, los movimientos del Sur están denunciando el 
carácter eurocéntrico del desarrollo, invitándonos a cambiar los términos del debate sobre la Modernidad: en vez de averiguar si son o no actores críticos de la modernidad, en lugar de evaluar si sus metas son ilustradas o pos-ilustradas, vale la pena rastrear cómo sus acciones han cuestionando los alcances de la Modernidad pero -y esto es muy importante- de la Modernidad tal y como se ha instalado en estas zonas del planeta”.

Partiendo de este postulado es posible encontrar en los movimientos indígenas latinoamericanos elementos potencialmente transformadores, no solo en cuanto buscan renovar el sentido común y las prácticas socioculturales, incorporando la revaloración por la diversidad, el respeto por la identidad y la cultura propia, etc., sino también en cuanto han sido capaces de postular una crítica profunda al ejercicio del poder y la autoridad del Estado, cuestionando la política vertical y a distancia que promueven las lógicas neoliberales e imperiales, posicionando una revaloración de los espacios locales, del control ciudadano, participativo y horizontal. Por último también han sido capaces de promover una mirada alternativa sobre el territorio, una concepción crítica del modelo desarrollista, la privatización de los recursos, la mercantilización generalizada y el saqueo medioambiental, postulando otras concepciones sobre el bienestar de las personas, para lo cual recurren a repertorios culturales subordinados, hasta entonces considerados como resabios de formas de vida tradicionales, atrasadas y primitivas, que la prepotencia del discurso moderno creía superados.

Sin duda las luchas y demandas indígenas pueden y han sido reducidas o traducidas por el poder en términos neoindigenistas, como demandas premodernas. No obstante no lo son. Son formas de articular un nuevo imaginario político, que apela a una retórica de tradición comunitaria distinta, a valores y conocimientos subordinados por el imaginario moderno/ colonial que permiten articular nuevas prácticas políticas y sociales. Son recursos para pensar un futuro distinto, transmoderno en el lenguaje de Dussel (2000), potencialmente mejor que el que ofrece la actual imposición del capital trasnacional, la degradación medioambiental, la pérdida de sentido y las democracias de baja intensidad en Latinoamérica. 


\section{Nota}

* El presente artículo recoge algunos elementos del trabajo de investigación realizado para la obtención del Máster en Estudios Latinoamericanos (2007-2009) de la Universidad de Salamanca, España, bajo la dirección del Dr. Salvador Martí i Puig. 


\section{Bibliografía}

Anderson, B. (1999), Comunidades imaginadas. Reflexiones sobre el origen y la difusión del nacionalismo. Fondo de Cultura Económica.

Assies, Calderón y Salman (2002), “Ciudadanía, cultura política y reforma del Estado en América Latina”. En Revista América Latina Hoy, 32, pp.55-90.

Balibar, E. y Wallerstein, I. (1991), Raza, nación y clase. IEPALA

Barrera, A. (2004), "Ecuador: el movimiento indígena entre lo social y lo político”. En Barataria, No 1, pp. 71-77.

Bengoa, J. (1999), Historia de un conflicto. El Estado y los mapuche en el siglo $X X$. Editorial Planeta, Santiago.

Castro-Gómez, S. (2000), “Ciencias sociales, violencia epistémica y el problema de la 'invención del otro' ”. En Lander (comp.) La colonialidad del saber: eurocentrismo y ciencias sociales. Perspectivas latinoamericanas. CLACSO, Buenos Aires.

Degregori, C. (1993), "Identidad étnica, movimientos sociales y participación política en el Perú”. En Adrianzén y otros (ed.), Democracia, etnicidad y violencia política en los países andinos. Lima.

Dussel, E. (2006), Filosofía de la cultura y la liberación. Universidad Autónoma de la Ciudad de México.

Ídem (2000), “Europa, modernidad y eurocentrismo”. En Lander (comp.) La colonialidad del saber: eurocentrismo y ciencias sociales. CLACSO.

Ídem (1998), Ética de la liberación. En la edad de la globalización y de la exclusión. Ed. Trotta, Madrid.

Escobar, A. (2005), Más allá del tercer mundo. Globalización y diferencia. ICANH, Bogotá.

Flórez-Flórez, J. (2007), “Lectura no eurocéntrica de los movimientos sociales latinoamericanos. Las claves analíticas del proyecto modernidad/ colonialidad”. En Castro-Gómez y Grosfoguel (editores) El giro decolonial. Reflexiones para una diversidad epistémica más allá del capitalismo global. Siglo del Hombre Editores.

Ídem (2005), “Aportes postcoloniales (latinoamericanos) al estudio de los movimientos sociales”. En Tabula Rasa, No 3, pp.71-96.

Hale, C. (2004), "Rethinking indigenous politics in the Era of the 'Indio Permitido' ", en NACLA Report on the Americas, September-October 2004, pp. 16-21. 
Lander, E. (2000), “Ciencias sociales: saberes coloniales y eurocéntricos”. En Lander (comp.) La colonialidad del saber: eurocentrismo y ciencias sociales. CLACSO.

Larraín, J. (1999), Identidad, razón y modernidad en América Latina. Ed. Andrés Bello, Santiago.

Máiz, R. (2005), El indigenismo político en América Latina. Obra Social Fundación "la Caixa”.

Martí i Puig, S. (2007), "Emergencia de lo indígena en la arena política: ¿un efecto no deseado de la gobernanza?, en Martí i Puig (ed.) Pueblos indígenas y política en América Latina. El reconocimiento de sus derechos y el impacto de sus demandas a inicios del siglo XXI. Barcelona: Fundación Cidob.

Mignolo, W. (2003), Historias locales/diseños globales. Colonialidad, conocimientos subalternos y pensamiento fronterizo. AKAL, Madrid.

Mora, M. (2007), “Los nuevos retos y posibilidades para los movimientos indígenas en Latinoamérica: enseñanzas desde Bolivia, Ecuador, Nicaragua y México”. En Martí i Puig (ed.) Pueblos indígenas y política en América Latina: el reconocimiento de sus derechos y el impacto de sus demandas a inicios del siglo XXI. CIDOB.

Pallares, A. (2007), “Contesting membership: citizenship, pluriculturalism(s), and the contemporary indigenous movement”. En Clark \& Becker (eds.) Highland Indians and the State in Modern Ecuador. Pittsburgh.

Quijano, A. (2005), “El ‘movimiento indígena’ y las cuestiones pendientes en América Latina”. En Revista Tareas, N 119, enero-abril. CELA, Centro de Estudios Latinoamericanos, pp. 31-62. Panamá.

Ídem (2000a), “Colonialidad del poder: eurocentrismo y América Latina”. En Lander (comp.) La colonialidad del saber: eurocentrismo y ciencias sociales. Perspectivas latinoamericanas. CLACSO, Buenos Aires.

Ídem (2000b), “Colonialidad del poder y clasificación social”. En Journal of World-Systems Research, VI, 2, summer/fall, 342-386. Special Issue: Festchrift for Immanuel Wallerstein- Part I.

Sousa Santos, B. (2007), La reinvención del Estado y el estado plurinacional. OSAL $\mathrm{N}^{\circ} 22$, CLACSO.

Ídem (2005), El milenio huérfano. Ensayos para una nueva cultura política. Ed. Trotta. 
Stefanoni, P. (2007), "Bolivia: entre la revolución y la salida pactada”. En Archipiélago No 1, pp. 47-50.

Toledo Llancaqueo, V. (2007), “Prima Ratio. Movilización mapuche y política penal. Los marcos de la política indígena en Chile 1990-2007”. Revista OSAL $N^{\circ} 22$.

Van Cott, D. (2005), From movements to parties in Latin America. The evolution of ethnic politics. Cambridge University Press, New York.

Wallerstein, I. (2003), El capitalismo histórico. Siglo XXI, quinta edición en español.

Ídem. (2006), Las incertidumbres del saber. Ed. Gedisa. Barcelona.

Wallerstein, I; Arrighi, G. y Hopkins, T. (1999), Movimientos antisistémicos. Madrid: Akal.

Zibechi, R. (2007), Dispersar el poder. Los movimientos como poderes antiestatales. Virus editorial.

Recibido: 08.11.2009

Aceptado: 05.05.2010 